\title{
Comparison of oral health behaviour between dental and non-dental undergraduates in a university in southwestern China_- - exploring the future priority for oral health education
}

\author{
Mingming $\mathrm{Li}^{1+}$, Zhiwu Wu ${ }^{1 \dagger}$, Rui Zhang ${ }^{1}$, Lei Lei ${ }^{1}$, Siqi Ye ${ }^{2}$, Ran Cheng ${ }^{1 *}$ (D) and Tao Hu ${ }^{1 *}$
}

\begin{abstract}
Background: Based on a national survey in 2015, people's oral health behaviour (OHB) has not kept up with the pace of knowledge and attitudes in China after decades of oral health education (OHE). Thus, we need to improve OHE to strengthen people's OHB. Undergraduates are regarded as the best candidates for the improvement of OHE. The objective of this study is to determine undergraduates' oral health status and existing problems in OHB by comparing dental and non-dental students at Sichuan University. We hope to provide some suggestions for future OHE to improve people's OHB.
\end{abstract}

Methods: A quasi-experimental study designed with a pre-test and post-test group was conducted. A total of 217 dental students and 135 non-dental students were enrolled. They were administered an OHE course focused on OHB. A survey about oral health behaviour and knowledge was conducted before and after the course.

Results: According to the pre-course survey, dental students surpassed non-dental students in terms of toothbrushing frequency, method, and time, but unfortunately, flossing was overlooked by all the students. After the course, both dental and non-dental students showed strong willingness to improve their OHB. More non-dental students than dental students were willing to use toothpicks and Chinese herbal toothpaste before and after the course.

Conclusions: OHE focused on behaviour has a positive effect on university students. Future OHE and interventions should focus on flossing, toothbrushing methods, toothpicks, Chinese herbal toothpaste and modifications to adopt new media.

Keywords: Oral health education, Oral health behaviour, Dental students, Non-dental students

\footnotetext{
* Correspondence: chengran@scu.edu.cn; hutao@scu.edu.cn

${ }^{+}$Mingming Li and Zhiwu Wu contributed equally to this work.

'Department of Preventive Dentistry, State Key Laboratory of Oral Diseases,

West China Hospital of Stomatology, Sichuan University, Chengdu, Sichuan,

China

Full list of author information is available at the end of the article
}

C C The Author(s). 2020 Open Access This article is licensed under a Creative Commons Attribution 4.0 International License, which permits use, sharing, adaptation, distribution and reproduction in any medium or format, as long as you give appropriate credit to the original author(s) and the source, provide a link to the Creative Commons licence, and indicate if changes were made. The images or other third party material in this article are included in the article's Creative Commons licence, unless indicated otherwise in a credit line to the material. If material is not included in the article's Creative Commons licence and your intended use is not permitted by statutory regulation or exceeds the permitted use, you will need to obtain permission directly from the copyright holder. To view a copy of this licence, visit http://creativecommons.org/licenses/by/4.0/. The Creative Commons Public Domain Dedication waiver (http://creativecommons.org/publicdomain/zero/1.0/) applies to the data made available in this article, unless otherwise stated in a credit line to the data. 


\section{Background}

Oral disease is a worldwide epidemic and has imposed an enormous burden on the health and economy of the whole society [1]. The number of people with untreated oral conditions worldwide increased from 2.5 million in 1990 to 3.5 billion in 2015, with a $64.0 \%$ increase in disability-adjusted life years due to oral conditions [2]. Among these conditions, untreated dental caries, severe periodontitis, and missing teeth are the three most common and chronic infectious oral diseases [1].

Fortunately, most oral diseases, especially dental caries and periodontal diseases, are largely preventable through various promotion interventions. Oral health education (OHE) was once considered the most cost-effective intervention [3]. In China, OHE has been conducted for years. The national campaign, "National Teeth Love Day", was established in 1989 and has proposed a topic for OHE every year [4]. After decades of effort, the national survey in 2015 showed that approximately $60.0 \%$ of citizens had basic knowledge regarding oral health, and $84.9 \%$ of them had a positive attitude [5]. However, the caries rates of children aged 3-5 years and elderly people aged 65-74 years were 62.5 and $98.0 \%$, respectively, which were much higher than the rates 10 years ago. In addition, $87.4 \%$ of adults between 35 and 44 years old suffered from gingival bleeding [5]. These findings may suggest that people's oral health behaviour $(\mathrm{OHB})$ has not improved with the pace of the knowledge and attitudes in China via OHE.
Some recent studies have indicated that among various interventions, motivational interviewing (MI) interventions and counselling interventions are effective in promoting $\mathrm{OHB}$, while $\mathrm{OHE}$ is effective for knowledge and attitude but ineffective, or have only a short-term effect, for behaviour [6, 7]. Some reviews have suggested that the psychology of behaviour change is the key to oral health promotion. MI is currently one of the most effective forms of psychological intervention [8]. However, some studies also suggest that the application of MI in dental healthcare shows a null effect or remains controversial $[9,10]$. More importantly, MI was developed for individual promotion in a clinical setting. It is worth noting that individual prevention may not be enough to achieve sustainable improvements at the population level [11]. In China, due to its large population, the lack of dentists, dental hygienists and medical resources (the dentist-to-population ratio is 1:10,000 in China [12]), MI may not be the most cost-effective method. Instead, $\mathrm{OHE}$ is more suitable. A recent study has suggested that the educational interventions carried out by health professionals still have the potential to promote $\mathrm{OHB}$ within the population [13]. Computer-aided, video-assisted, text-message-assisted and quantitative light-induced fluorescence technology-based learning in OHE has recently been shown to have positive impacts on behaviour [14-17]. Thus, based on our current situation, we still have room to improve OHE to strengthen people's oral health, especially OHB.

\section{Majors of non-dental students}
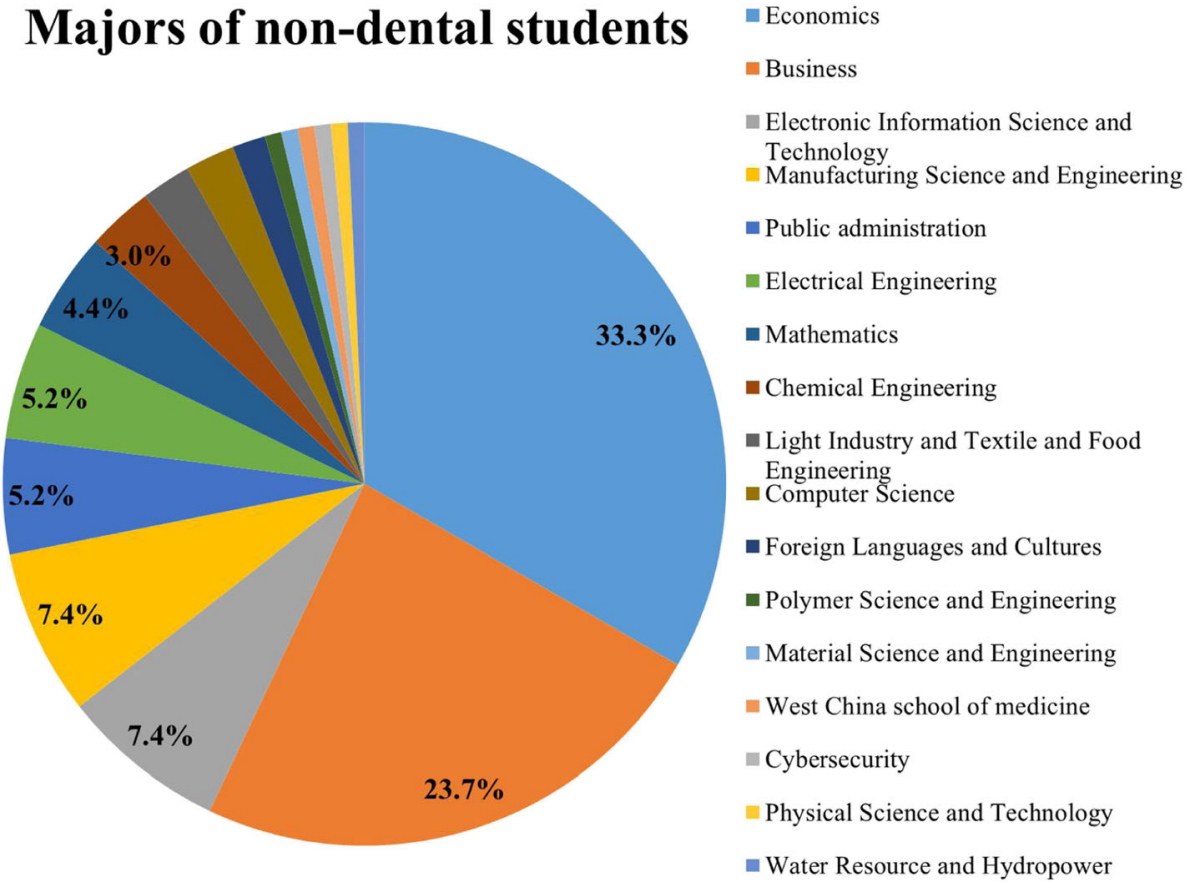

Fig. 1 Majors of the non-dental students. The top four were the Department of Economics, Business, Electronic Information Science and Technology and Manufacturing Science and Engineering 


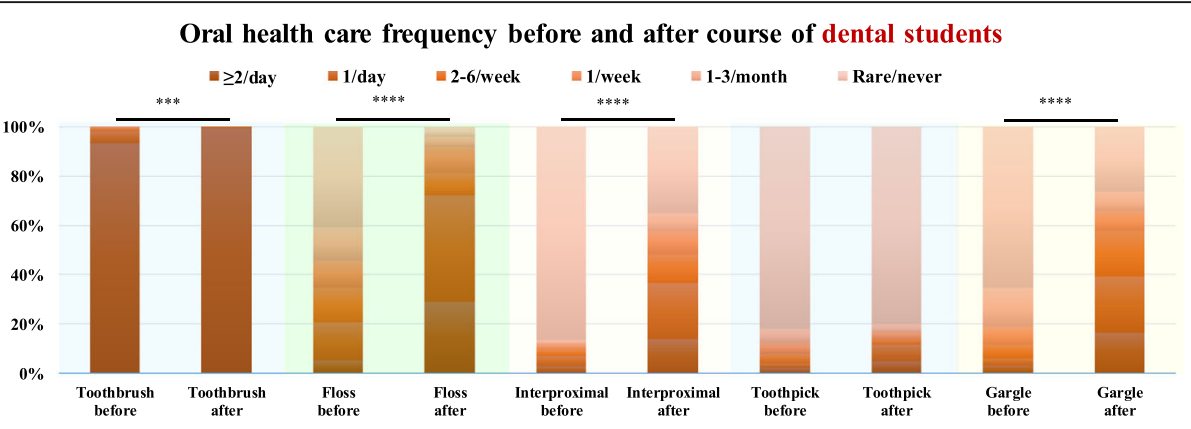

(a)

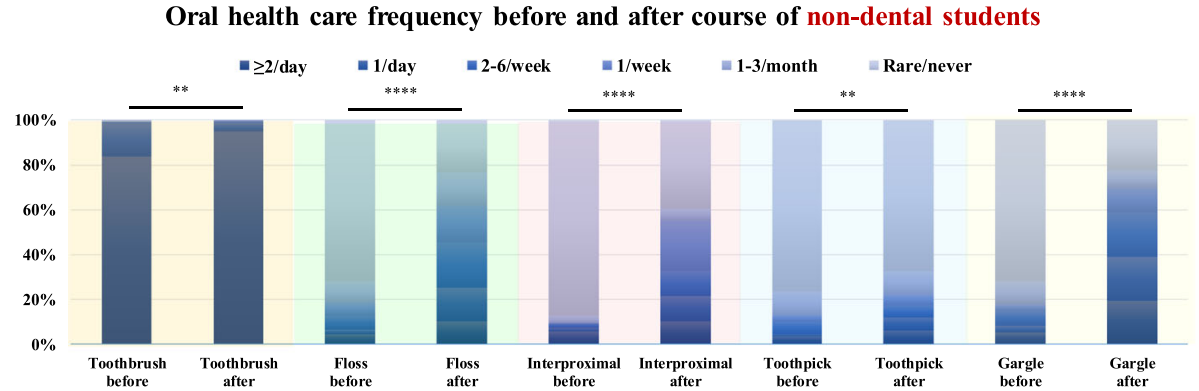

(b)

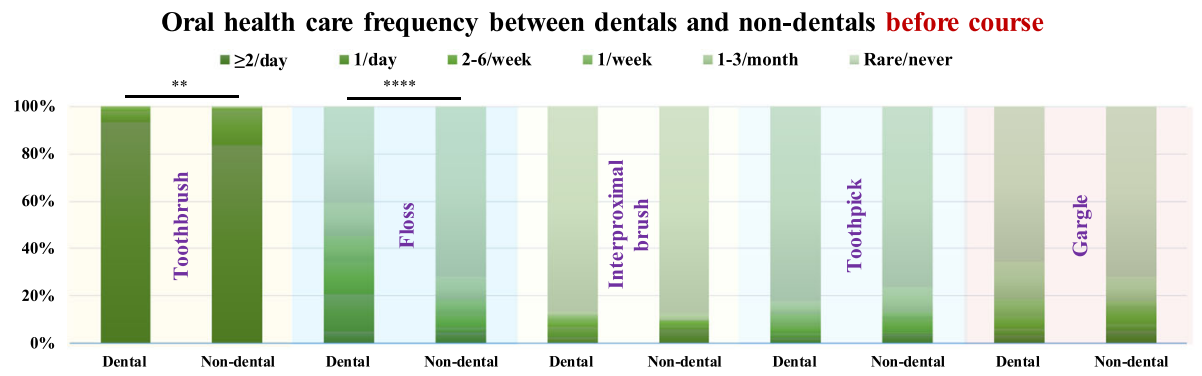

(c)

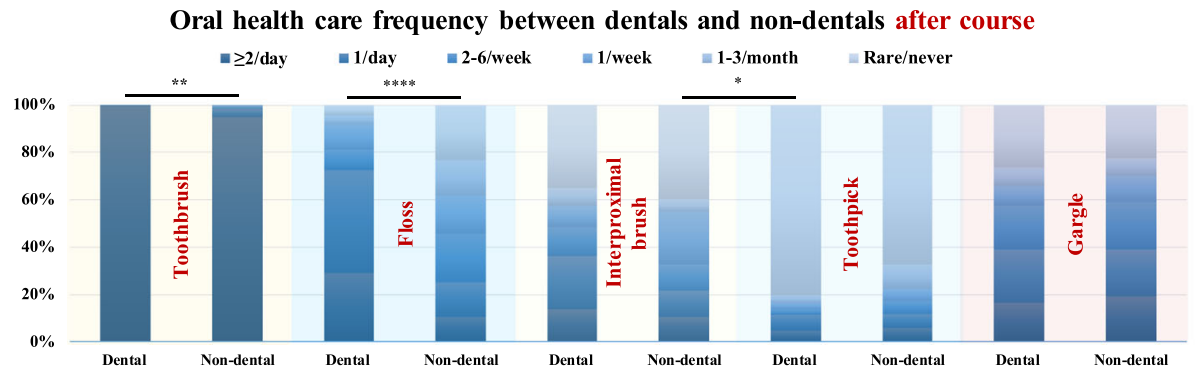

(d)

Fig. 2 Oral health care frequency of dental students and non-dental students before and after the course. $\mathbf{a}$, $\mathbf{b}$ Dental and non-dental students improved greatly in toothbrushing and interproximal cleaning after the OHE-related course. $\mathbf{c}$, $\mathbf{d}$ Dental students surpassed non-dental students in toothbrushing $(P=0.004)$ and flossing $(P=0.000)$ before and after the course. Non-dental students were more willing to use toothpicks after the course $(P=0.016)$. (Wilcoxon signed-rank test; $\left.{ }^{* * *}, P=0.000 ;{ }^{* *}, P=0.01 ; *, P<0.05\right)$

Since 2016, several oral-related policies have been enacted to improve OHE in China. For example, OHE should be improved in preschool and primary school [18]. However, children are often too young to accept OHE and fail to do well in OHB. Their oral health mainly depends on their parents' correct 
guidance over a long period of time [19]. Many surveys have revealed that parents' behaviours are associated with children's OHB [20-22]. China is also facing an ageing and undereducated population and an upcoming socio-economic burden resulting from the elderly population [23, 24]. Several reports have shown that oral health is positively correlated with education $[25,26]$. The offspring of elderly people may contribute to improving the health of their parents by transferring knowledge and practices [27-29]. As a result, undergraduates might be the best candidates for OHE. First, they are well educated and more receptive to OHE. It has been verified that OHE positively changes the behaviour of college students [30]. Second, younger adults can act as OHE assistants for their parents. In-school undergraduates aged between 18 and 22 years are at an important phase of transition from adolescence to adulthood [31]. They will become parents in a few years and be beneficial to their future children. The earlier OHB is established, the more benefits it will bring about, and the longer it will be retained [30]. Third, it is comparably easy to arrange $\mathrm{OHE}$ in school.

However, according to the WHO guidelines, the undergraduate group was not included in the Chinese national survey. Their oral health status was unknown for years. It is necessary to know the current status of their oral health and the existing problems concerning OHB. In this survey, the differences in oral health behaviour and knowledge between dental and non-dental students at Sichuan University were compared to identify the current problems in $\mathrm{OHB}$ and to provide advice for better OHE.

\section{Methods}

\section{Participants}

Third-year undergraduate dental students (in the first year of their professional dental education) were enrolled. The inclusion criteria were a) third-year dental students at Sichuan University and b) agreement to participate in the survey. The exclusion criterion was incorrectly written answers.

Second- to fourth-year non-dental students were also enrolled. The inclusion criteria were a) students at $\mathrm{Si}$ chuan University and b) agreement to participate in the survey. The exclusion criteria were a) dental students and b) incorrectly written answers.

A pre-test was conducted on the toothbrushing frequency of dental and non-dental students. In order to estimate the sample size, the method "difference test of rate comparison between two groups" was chose and the calculator $(1+1 / k)\left(\mu_{\alpha}+\mu_{\beta}\right)^{2} p(1-p) / \delta^{2}$ was applied [32] ( $\left.p=\frac{p 1+k p 2}{1+k}, p 1=0.97, p 2=0.86\right)$. The sample size was estimated to be more than 110 in each group.

\section{Design}

A quasi-experimental survey with a pre-test and a posttest group was conducted for the study. (The survey questionnaires are supplemented as additional files at the end of the article).

\section{Intervention and instruments}

The dental and non-dental students received the precourse survey on knowledge and behaviour of oral health before the lecture. The OHE was scheduled in a 90-min course by the same teacher. The content was designed based on the textbook "Preventive Dentistry" [2] and focused on the aetiology of common oral diseases and specific oral hygiene measures with the aim of improving students' OHB. Non-dental students had the same course in the part of "behavioural guidance" as dental students. A post-course survey including the same items was conducted.

\section{Data collection and analysis}

All the students finished the questionnaires by cell phone or by computer through "Questionnaire Star", a professional online survey, measurement and voting platform. For the scale items in the questionnaire, we used SPSS 16.0 (IBM Corp. New York, NY, USA) to analyse the Cronbach's alpha coefficient. Six experts (1 professor, 3 associate professors and 2 lecturers) evaluated the content validity [33], clarity, and conciseness of the questionnaires. The data are presented as percentages, means and standard deviations (SDs). The Wilcoxon signed-rank test, chi-square test and Fisher's exact test were used for statistical analysis with SPSS 16.0. $P<0.05$ was regarded as a statistically significant difference.

\section{Results}

In the pre-course survey, 217 third-year undergraduate dental students (86 male, 131 female; aged $21.3 \pm 1.0$ years) and 135 non-dental students (55 male, 80 female; aged $21.4 \pm 0.8$ years) were enrolled. In the post-course survey, 1 student in the non-dental group was excluded as a result of incorrect writing. The non-dental students were in the second to fourth years. They were from 17

Table 1 The knowledge about water/air flossing

\begin{tabular}{llll}
\hline & Dental students & Non-dental students & $P^{\mathrm{a}}$ \\
\hline Before lecture & $2.83 \pm 1.17$ & $2.51 \pm 1.05$ & 0.000 \\
After lecture & $4.51 \pm 0.51$ & $4.31 \pm 0.55$ & 0.000 \\
$P^{\mathrm{b}}$ & 0.000 & 0.000 & \\
\hline
\end{tabular}

Wilcoxon signed-rank test; Scale: 1 (strongly unknown) to 5 (strongly knowledgeable)]

${ }^{\text {a }}$ Comparison between dental and non-dental students before and after class

${ }^{b}$ Comparison between students before and after class 


\section{Toothbrushing methods}

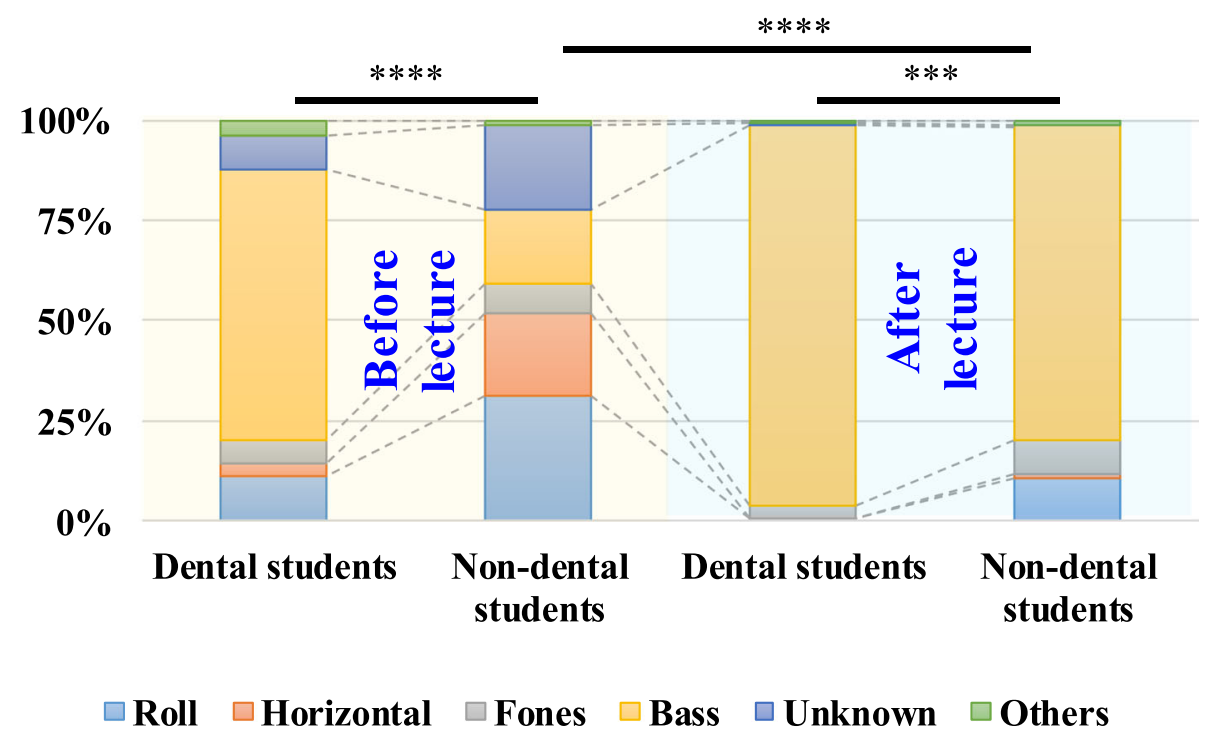

(a)

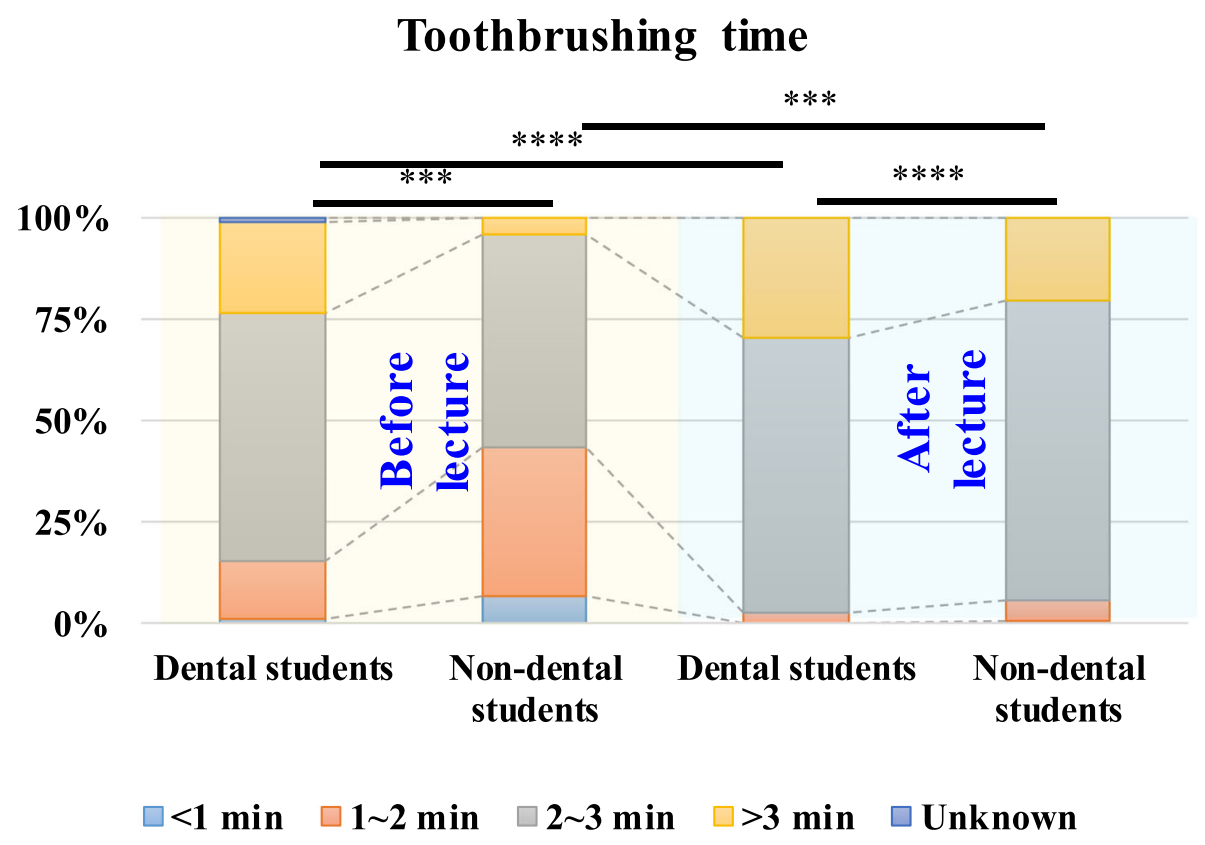

(b)

Fig. 3 The choice of toothbrushing methods and time. a Dental students overwhelmed non-dental students in the use of the Bass method ( $P=0.000)$. A total of $20.7 \%$ of non-dental students were using the wrong horizontal method. $\mathbf{b}$ Dental students performed generally better than non-dental students in toothbrushing time before $(P=0.000)$ and after $(P=0.025)$ the course (Wilcoxon signed-rank test; $\left.{ }^{* * *}, P=0.000 ;{ }^{* * *}, P=0.001\right)$

departments of Sichuan University, and their majors are displayed in Fig. 1.

Reliability analysis of the scale items of a simultaneous survey showed that the Cronbach's alpha coefficient was
0.781 for the pre-course survey and 0.711 for the postcourse survey. For non-scale items in this survey, the reliability was considered acceptable when the same group completed the questionnaires at the same time. A 
content validity index (CVI) was calculated for the questionnaire items. The item-level CVIs and the scale-level CVIs were 1.

First, we surveyed the oral health care frequency of dental and non-dental students (Fig. 2). Before the course (Fig. 2c), most students in both groups did well at brushing their teeth twice a day. Up to $71.9 \%$ of students in the non-dental group and $40.6 \%$ in the dental group never used floss (Fig. 2c). However, the dental group was still significantly better than the non-dental group $(P=0.000)$. There was no obvious difference between the two groups in the use of interproximal brushes or toothpicks $(P>0.05)$. After the course (Fig. $2 \mathrm{~d}$ ), students tended to brush their teeth twice a day, with an obvious increase in both groups $(P=0.001$ in the dental group, $P=0.004$ in the non-dental group). The dental group was more willing to use dental floss or to use it more often $(P=0.000)$. However, one-fifth of the non-dental students were still reluctant to floss. Compared to dental students, non-dental students were more willing to use toothpicks $(P=0.016)$. In short, the dental group performed better than the non-dental group in toothbrushing and flossing before and after the course. Table 1 shows students' knowledge about water/ air flossing. Before the course, both groups were unfamiliar with these tools. The course introduced new flossing equipment to them.

Next, we surveyed the toothbrushing method (Fig. 3a). The number of dental students using the Bass method overwhelmed that of non-dental students $(P=0.000)$. One-fifth of the non-dental students were still using the wrong horizontal method, and one-fifth did not know the in-use methods. Table 2 shows the knowledge of the Bass method between the two groups. The results revealed that dental students performed much better than non-dental students before $(P=0.000)$ and after $(P=$ $0.000)$ the course. Regarding brushing time (Fig. 3b), dental students performed generally better than nondental students before $(P=0.000)$ and after $(P=0.025)$ the course. The number of students who were willing to brush their teeth for more than 2 min increased in the two groups after the course $(P=0.001$ in the dental group, $P=0.000$ in the non-dental group).

Table 2 Knowledge of the modified Bass method

\begin{tabular}{llll}
\hline & Dental students & Non-dental students & $P^{\text {a }}$ \\
\hline Before lecture & $4.23 \pm 0.75$ & $2.83 \pm 1.16$ & 0.000 \\
After lecture & $4.75 \pm 0.44$ & $4.35 \pm 0.49$ & 0.000 \\
$\boldsymbol{P}^{\mathbf{b}}$ & 0.000 & 0.000 &
\end{tabular}

Wilcoxon signed-rank test; Scale: 1 (strongly unknown) to 5 (strongly knowledgeable)]

${ }^{\text {a }}$ Comparison between dental and non-dental students before class

${ }^{b}$ Comparison between students before and after class
We further investigated the types and replacement frequency of toothbrushes (Fig. 4). Before the course, more than half of the students in both groups preferred electric toothbrushes to manual toothbrushes (Fig. 4a). However, the actual usage or willingness to use was lower (Fig. 4b). After the course, more dental students thought electric toothbrushes were better and wanted to use them. With regard to the softness of bristles (Fig. 4c), soft-bristled toothbrushes were favoured after the course $(P=$ 0.01 in the dental group, $P=0.012$ in the non-dental group). Toothbrushes need to be replaced regularly, and most students had a good habit of changing their toothbrushes every 3 months (Fig. $4 \mathrm{~d}$ ). There was no obvious difference in these 2 items between the two groups $(P>0.05)$.

Finally, we examined students' considerations when selecting toothbrushes and toothpaste (Fig. 5). Before the course, function and price were the aspects of concern for most students (Fig. 5a, b). After the course, in both groups, more students realized the importance of function $(P=0.000)$, fewer students cared about popularity $(P=0.000)$ and fewer students were confused about choosing toothbrushes and toothpaste $(P=0.000)$. Regarding the function of toothpaste (Fig. $5 \mathrm{c}$ ), non-dental students preferred Chinese herbs, whitening and fluoride toothpastes before the course, while dental students preferred fluoride, Chinese herbs and desensitizing toothpastes. After the course, more students chose fluoridated and desensitizing toothpaste in both groups $(P=0.000)$. Fewer dental students $(P=0.000)$ and more non-dental students $(P=0.000)$ were willing to use Chinese herbal toothpaste, and the two groups showed opposite trends.

\section{Discussion}

The 4th Chinese National Oral Health Survey showed that people's oral health knowledge and attitudes had been greatly improved, but caries and periodontal diseases remained serious problems, and people's OHB was far from standard. OHE focused on behaviour for undergraduates, with the aim of helping them improve themselves and indirectly helping children and elderly people, might be an efficient way of addressing this issue.

A previous study showed that the oral healthcare knowledge and behaviour of dental students were better than those of non-dental students [34]. For dental students at Sichuan University, they underwent oral health education starting in their first year. Some clinical research or practice was open to them, such as the university students' innovation and entrepreneurship training programme. Additionally, some of them had opportunities to get in touch with seniors and obtain additional information. The third year is the first year of professional dental education. Preclinical education and practice can enhance dental students' knowledge and 


\section{which toothbrush is better}

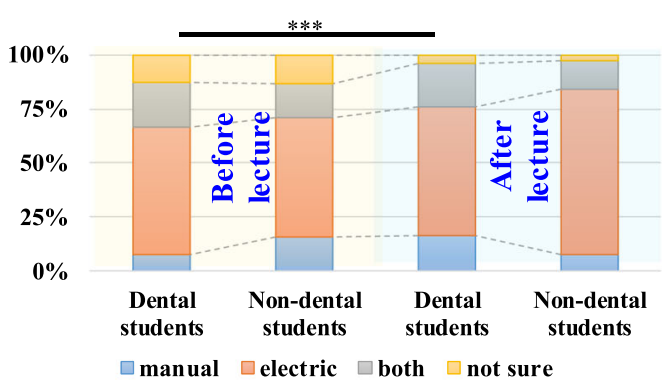

(a)

The toothbrush in use/ intend to use

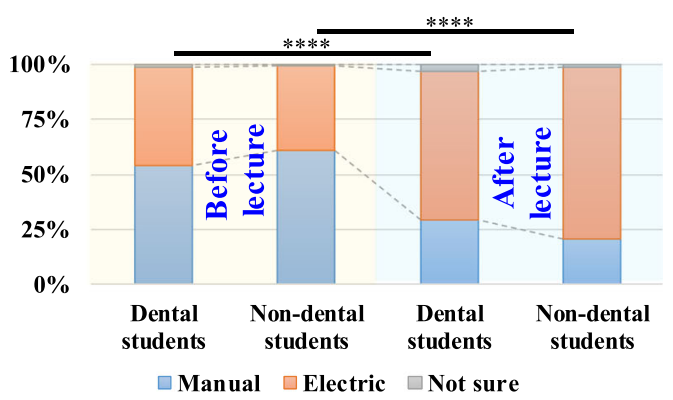

(b)

The toothbrush bristle in use/intend

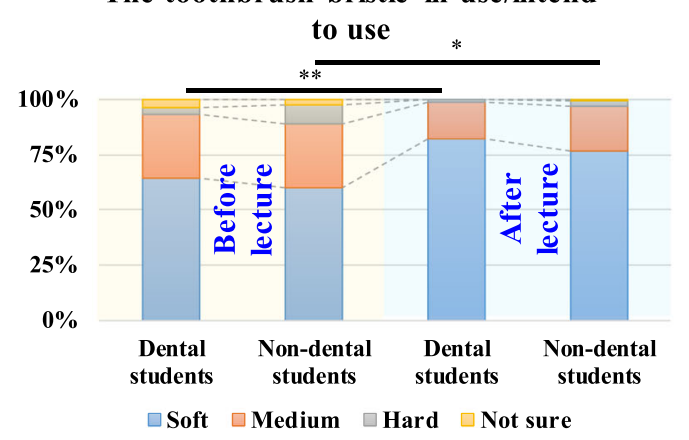

(c)

\section{The frequency of changing} toothbrush

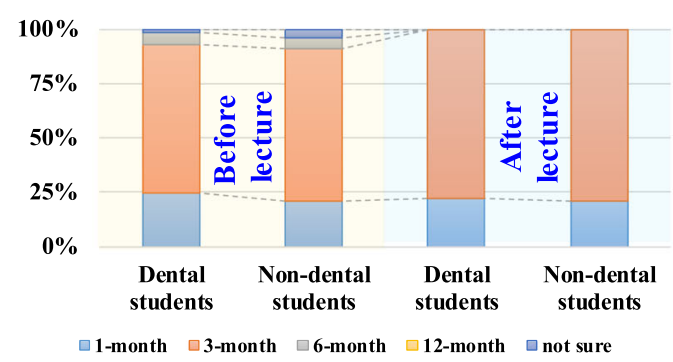

(d)
Fig. 4 The types and replacement frequency of toothbrushes of dental students and non-dental students. $\mathbf{a}, \mathbf{b}$ Before the course, most students in both groups preferred electric toothbrushes to manual toothbrushes. However, the actual usage of electric toothbrushes was low. After the course, more dental students thought electric toothbrushes were better. c Soft-bristled toothbrushes were favoured by more students after the course. $\mathbf{d}$

There was no obvious difference in the frequency of changing toothbrushes between the two groups $(P>0.05)$ (Wilcoxon signedrank test; $\left.{ }^{* * *}, P=0.000 ;{ }^{* * *}, P=0.001 ;{ }^{* *}, P=0.01 ;{ }^{*}, P<0.05\right)$

behaviour of oral health. For non-dental students who had similar general education backgrounds as those of dental students, the difference might come from preclinical oral health education. Therefore, we used the dental group as a reference to identify the differences or gaps in $\mathrm{OHB}$ between the two groups. Additionally, we explored the role of OHE focused on OHB in both dental and non-dental students by comparing their oral health knowledge and attitudes before and after the course. Regarding the behaviour guidance part of the course, non-dental students experienced the same content and degree of difficulty as did dental students. Although this relatively-professional education was more difficult than usual, it was helpful for non-dental students to understand aetiology-based knowledge and might also be helpful for behavioural education.

Toothbrushing frequency was well known among all the students. However, half of the non-dental students did not meet the recommended brushing time of $2 \mathrm{~min}$. Additionally, non-dental students faced difficulty in selecting a tooth brushing method. The (modified) Bass method, Roll method, Fones method and horizontal method are the most widely used brushing methods [35]. A study has shown that the (modified) Bass technique is effective in controlling dental plaque and alleviating gingival inflammation [36]. The horizontal method, which could result in wedge-shaped defects, is not recommended. However, it is a common method used in China. In this survey, less than one-fifth of the nondental students used the Bass method, but more than two-fifths of them used incorrect methods. From these results, we concluded that although non-dental students had good brushing frequency, their brushing time and actual brushing methods may not be appropriate.

Interproximal cleaning was extremely overlooked by both dental and non-dental students. It was surprising that few dental students floss daily. The findings revealed signs of ignorance concerning interproximal cleaning in China. Using floss in addition to toothbrushing may reduce gingivitis, plaque, or both, more than toothbrushing alone [37]. However, floss is comparably 


\section{How to choose toothbrushes}

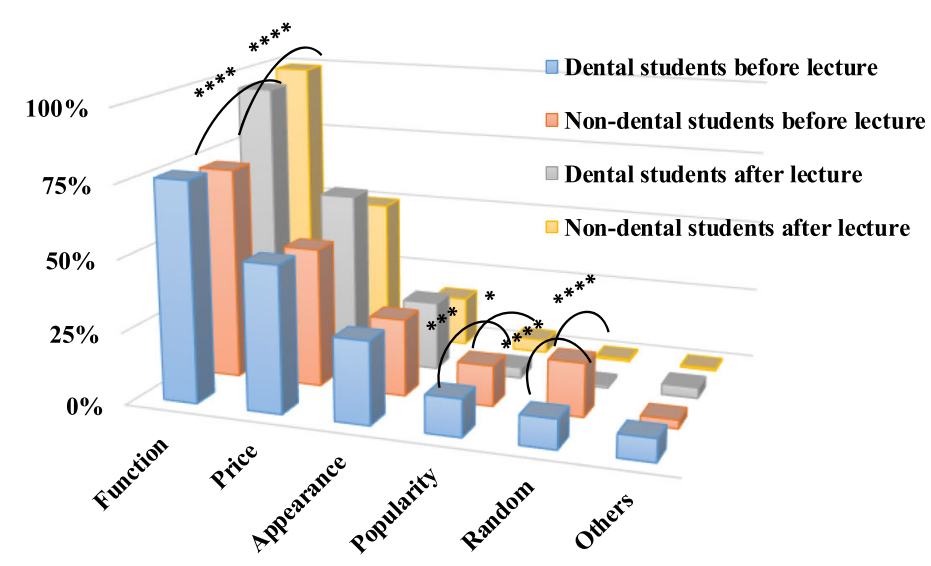

(a)

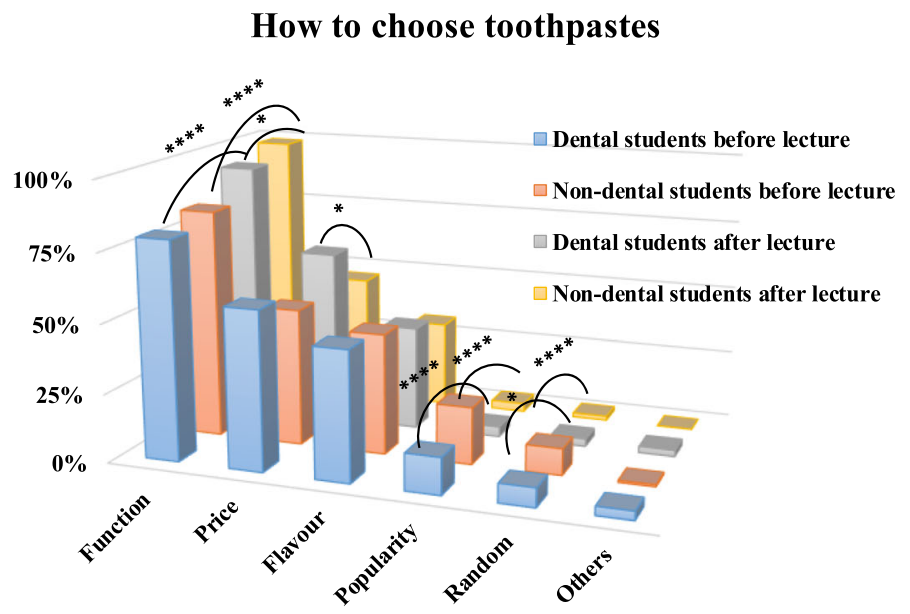

(b)

\section{Types of toothpastes}

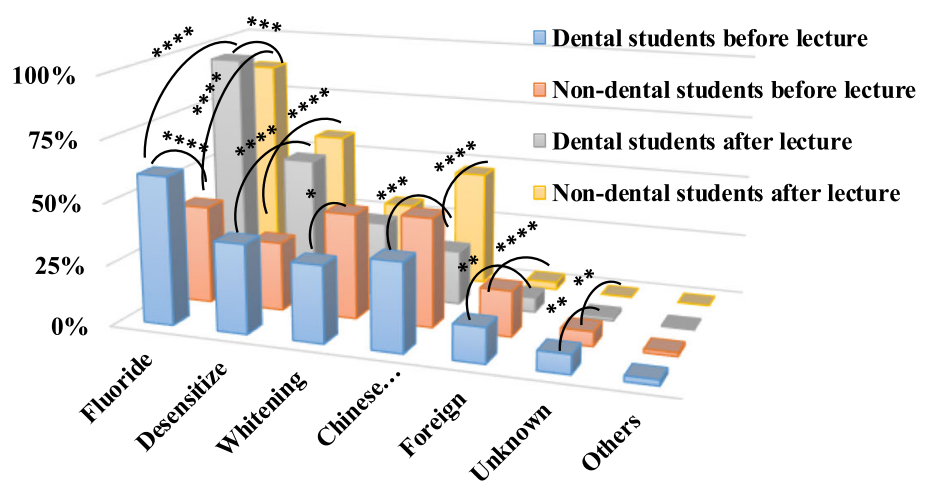

(c) 
(See figure on previous page.)

Fig. 5 Dental students' and non-dental students' considerations when selecting toothbrushes and toothpaste before and after the course. a, $\mathbf{b}$ Function and price were the first two considerations. Some students cared about popularity before the course. c Non-dental students preferred Chinese herbs, whitening and fluoride toothpastes before the course, while dental students preferred fluoride, Chinese herbs and desensitizing toothpastes. After the course, fewer dental students and more non-dental students were willing to use Chinese herbal toothpaste $(P=0.000)$, and the two groups showed opposite trends (chi-square test or Fisher's exact test; ${ }^{* * *}, P=0.000 ;{ }^{* * *}, P=0.001 ; * *, P=0.01 ;{ }^{*}, P<0.05$ )

difficult to use, which may limit its application [38]. Moreover, toothpicks have a history of more than a thousand years in China and are deeply rooted in Chinese people's minds [39]. Toothpicks are quite popular in China and can easily be found in restaurants and takeaway cutlery. Interestingly, the tendency to use toothpicks increased among non-dental students after the course. OHE on avoiding the use of toothpicks should be strengthened to minimize the periodontal damage caused by improper use.

Function and price were the most important considerations when students chose toothbrushes. A study confirmed that electric toothbrushes were more effective than manual toothbrushes [40]. Before the course, more than half of the students in both groups thought electric toothbrushes were better than manual toothbrushes. However, the actual use rate was much lower, especially in the non-dental group. Furthermore, nationwide usage was much lower. A report showed that the penetration rate of electric toothbrushes in China was only 5\%, while in some developed countries, it was more than $15 \%$ and even up to $40 \%$ [41]. Price might be a possible reason for this result. After the introduction of electric toothbrushes during the course, more students realized their advantages and intended to use them, even at a higher price. If electric toothbrushes are not popular because of their high price, then we should strengthen OHE on the use of manual toothbrushes instead of emphasizing the use of electric toothbrushes.

When choosing toothpaste, function and price were the first two considerations. Interestingly, more nondental students than dental students were willing to use Chinese herbal toothpaste before and after the course. As a part of traditional Chinese medicine, Chinese herbal toothpaste may have some effects in alleviating gingival inflammation [42] and preventing caries [43]. Chinese have partiality for Chinese herbal toothpaste. Its correct usage should be addressed in future OHE courses; for example, when facing gingival bleeding caused by periodontitis, relying on herbal toothpaste instead of scaling may worsen the disease.

One issue that cannot be ignored is that some students cared about popularity when choosing toothpaste and toothbrush. This suggests a new method of OHE: new media. Recently, a large number of popular media platforms have emerged. WeChat, an interactive social media platform in China, has a wide range of young users and is used every day [44]. A study showed that the passive acquisition (moments, public accounts, and group chat) of health information through WeChat is an important medium for college students [45]. Taobao, a large online shopping platform, is preferred by young people and carries many traditional and emerging oral care products endorsed by celebrities, which is very attractive to young people who are starstruck and pursuing popularity. At the same time, it contains a wealth of pictures, videos and instructions for the products. In addition to traditional classes, WeChat groups, WeChat public accounts and Moments can be used for regular OHE as a reminder to floss and as an update to new knowledge that is not included in textbooks. Taobao links can provide vivid information about oral hygiene products, making OHE much more convenient and cost-effective.

Overall, the majority of students realized their shortcomings in $\mathrm{OHB}$ and had a strong willingness to improve. Our OHE course focused on behaviour had a positive effect on university students. Dental students had much better performance than non-dental students in terms of toothbrushing frequency, method, and time and floss use. This suggests that dental students know more details about oral healthcare. Future OHE should pay more attention to flossing, toothbrushing methods, toothpicks, Chinese herb toothpaste and modifications to adopt new media.

\section{Limitations}

As a quasi-experimental study, the grades and sample numbers of dental and non-dental students were different. The post-course survey was conducted within a short period of time. The long-term change in students' knowledge, attitudes and behaviours is unknown. Furthermore, our survey did not include clinical examinations.

\section{Conclusions}

According to the pre-course survey, dental students significantly surpassed non-dental students in terms of toothbrushing frequency, method, and time, but floss was overlooked by all the students. After the course, both dental and non-dental students showed strong willingness to improve their OHB. Future OHE should focus on flossing, toothbrushing methods, toothpicks, Chinese herbal toothpaste and modifications to adopt new media. 


\section{Supplementary information}

Supplementary information accompanies this paper at https://doi.org/10. 1186/s12903-020-01232-1.

Additional file 1. Pre-class Questionnaire.

Additional file 2. Post-class Questionnaire.

\section{Abbreviations}

OHE: Oral health education; OHB: Oral health behaviour; CVI: Content validity index

\section{Acknowledgements}

The authors thank Linglin Zhang for her help in arranging the course. And we also thank all students who participated in our procedures.

\section{Authors' contributions}

$\mathrm{RC}$ and $\mathrm{TH}$ contributed to the design of the study. $\mathrm{LL}$ contributed to the design of the questionnaires. ML and ZW devoted to the data collection, analysis and manuscript writing. RZ assisted data collection. RC, TH and SY contributed to manuscript revisions. All authors committed themselves to the crucial revision of the paper and supported the final manuscript for publication. The author(s) read and approved the final manuscript.

\section{Funding}

The study was supported by the "Innovation Training Project from SCU Training Programs of Innovation and Entrepreneurship for Undergraduates" (C2020107885), the "Research of Graduate Education Reform of Sichuan University (2019)" (Nos YJSJG006) and the "Sichuan Science Popularization Project" (2020JDKP0018).

\section{Availability of data and materials}

The main data used to support the findings of this study is included within the article. The datasets generated and analysed during the current study are available from the corresponding author (chengran@scu.edu.cn) on reasonable request.

\section{Ethics approval and consent to participate}

This study was supported by the Institutional Review Board of the Ethics Committee of West China Hospital of Stomatology, Sichuan University (WCHSIRB-D-2018-092). All the participating students had signed informed consent.

\section{Consent for publication}

Not applicable.

\section{Competing interests}

$M L, Z W, R Z, L L, S Y, R C$ and $T H$ state that they have no conflict of interest.

\section{Author details}

'Department of Preventive Dentistry, State Key Laboratory of Oral Diseases, West China Hospital of Stomatology, Sichuan University, Chengdu, Sichuan, China. ${ }^{2}$ West China school of Stomatology, Sichuan University, Chengdu, Sichuan, China.

Received: 13 April 2020 Accepted: 24 August 2020

Published online: 07 September 2020

\section{References}

1. Jin LJ, Lamster IB, Greenspan JS, Pitts NB, Scully C, Warnakulasuriya S. Global burden of oral diseases: emerging concepts, management and interplay with systemic health. Oral Dis. 2016;22(7):609-19.

2. Kassebaum NJ, Smith AGC, Bernabe E, Fleming TD, Reynolds AE, Vos T, Murray CIL, Marcenes W. Global, regional, and national prevalence, incidence, and disability-adjusted life years for oral conditions for 195 countries, 1990-2015: a systematic analysis for the global burden of diseases, injuries, and risk factors. J Dent Res. 2017;96(4):380-7.

3. Habbu SG, Krishnappa P. Effectiveness of oral health education in children a systematic review of current evidence (2005-2011). Int Dent J. 2015;65(2): $57-64$.
4. Hu DY. Preventive Dentistry. 6th ed. Beijing: People's Medical Publishing House; 2012.

5. Wang $X$, Feng XP, Li ZX. The fourth Chinese National Dental Health Survey report. 1st ed. Beijing: People's Medical Publishing House; 2018.

6. Kay E, Vascott D, Hocking A, Nield H, Dorr C, Barrett $H$. A review of approaches for dental practice teams for promoting oral health. Community Dentist Oral Epidemiol. 2016;44(4):313-30.

7. Ghaffari M, Rakhshanderou S, Ramezankhani A, Buunk-Werkhoven YAB, Noroozi M, Armoon B. Are educating and promoting interventions effective in oral health?: a systematic review. Int J Dent Hyg. 2018;16(1):48-58.

8. Kay EJ, Vascott D, Hocking A, Nield H. Motivational interviewing in general dental practice: a review of the evidence. Br Dent J. 2016;221(12):785-91.

9. Gao XL, Lo ECM, Kot SCC, Chan KCW. Motivational interviewing in improving oral health: a systematic review of randomized controlled trials. J Periodontol. 2014:85(3):426-37.

10. Frost H, Campbell P, Maxwell M, O'Carroll RE, Dombrowski SU, Williams B, Cheyne $\mathrm{H}$, Coles $\mathrm{E}$, Pollock A. Effectiveness of motivational interviewing on adult behaviour change in health and social care settings: a systematic review of reviews. PLoS One. 2018;13(10):39.

11. Cascaes AM, Bielemann RM, Clark VL, Barros AJD. Effectiveness of motivational interviewing at improving oral health: a systematic review. Rev Saude Publica. 2014;48(1):142-53.

12. Liu J, Zhang SS, Zheng SG, Xu T, Si Y. Oral health status and oral health care model in China. Chin J Dent Res. 2016;19(4):207-15.

13. Menegaz AM, Silva AER, Cascaes AM. Educational interventions in health services and oral health: systematic review. Rev Saude Publica. 2018;52:14.

14. Ab Malik N, Zhang JG, Lam OLT, Jin LJ, McGrath C. Effectiveness of computer-aided learning in oral health among patients and caregivers: a systematic review. J Am Med Inf Assoc. 2017;24(1):209-17.

15. Ali AA, Miller ET. Effectiveness of video-assisted debriefing in health education: an integrative review. J Nurs Educ. 2018;57(1):13.

16. Toniazzo MP, Nodari D, Muniz F, Weidlich P. Effect of mHealth in improving oral hygiene: a systematic review with meta-analysis. J Clin Periodontol. 2019:46(3):297-309.

17. Khudanov B, Jung HI, Kahharova D, Lee JW, Hamidov I, Lee ES, Kim BI. Effect of an oral health education program based on the use of quantitative lightinduced fluorescence technology in Uzbekistan adolescents. Photodiagn Photodyn Ther. 2018;21:379-84.

18. The General Office of State Council of China. National Program for Chronic Disease Control and Prevention(2017-2025). http://www.govcn/zhengce/ content/2017-02/14/content_5167886htm. Accessed 15 Feb 2020.

19. SDCEP. Prevention and management of dental caries in children. 2nd ed; 2018.

20. George A, Sousa MS, Kong AC, Blinkhorn A, Norrie TP, Foster J, Dahlen HG, Ajwani $\mathrm{S}$, Johnson $\mathrm{M}$. Effectiveness of preventive dental programs offered to mothers by non-dental professionals to control early childhood dental caries: a review. BMC Oral Health. 2019:19(1):9.

21. Zacharias S, Kahabuka FK, Mbawalla HS. Effectiveness of randomized controlled field trial instructing parents to supervise children on tooth brushing skills and oral hygiene. Open Dentistry J. 2019;13:76-84.

22. Clarke R, Shaw-Ridley M. Parental attitudes and beliefs about preschooler preventive oral health behaviors: implications for health promotion. J Immigr Minor Health. 2019:21(4):731-6.

23. Zhang HK. The education level of the elderly in China and its changes. Chin J Gerontol. 2016;36(5):1215-6.

24. Banister J, Bloom DE, Rosenberg L. Population aging and economic growth in China. Pgda Working Papers. 2010;23(01):61-89.

25. Yang HJ, Seo WS. Differences in oral health behavior and quality of life among the elderly depending on income and education levels. J Korean Soc Dent Hyg. 2018;18(2):217-26.

26. Agustina D. The influence of educational level on the correlation between oral health status and oral health-related quality of life (OHRQoL) in Indonesian elderly. Australas Ageing. 2014;33:32

27. Ma MM. Does children's education matter for parents' health and cognition? Evidence from China. J Health Econ. 2019;66:222-40.

28. Yahirun JJ, Sheehan CM, Hayward MD. Adult Children's education and parents' functional limitations in Mexico. Res Aging. 2016;38(3):322-45.

29. Friedman EM, Mare RD. The schooling of offspring and the survival of parents. Demography. 2014;51(4):1271-93.

30. Potdar S, Lakshminarayan N, Reddy SG. Relationship of locus of control with plaque and gingival status before and after oral health education in a 
group of college students - an experimental study. Int J Dent Hyg. 2015; 13(1):42-8.

31. Schulenberg J, Maggs J, Hurrelmann K. Health risks and developmental transitions during adolescence. New York: Cambridge University Press; 1997.

32. Fang JQ. Statistical methods for biomedical research. 1st ed. Beijing: Higher Education Press; 2007.

33. Polit DF, Beck CT, Owen S. Is the CVI an acceptable indicator of content validity? Appraisal and recommendations. Res Nurs Health. 2007;30(4):45967.

34. Jeong M-K, Kim Y-M, Hong S-Y. A study on the oral health behavior of some dental hygiene students and other majors. J Korean Soc Dent Hyg. 2011;11(5):615-27.

35. Wainwright J, Sheiham A. An analysis of methods of toothbrushing recommended by dental associations, toothpaste and toothbrush companies and in dental texts. Br Dent J. 2014;217(3):E5.

36. Ausenda F, Jeong N, Arsenault P, Gyurko R, Finkelman M, Dragan IF, Levi P $J$ r. The effect of the bass intrasulcular toothbrushing technique on the reduction of gingival inflammation: a randomized clinical trial. J Evid-Based Dent Pract. 2019;19(2):106-14

37. Worthington HV, MacDonald L, Pericic TP, Sambunjak D, Johnson TM, Imai P, Clarkson JE. Home use of interdental cleaning devices, in addition to toothbrushing, for preventing and controlling periodontal diseases and dental caries. Cochrane Database Syst Rev. 2019;4:204.

38. Fischman SL. The history of oral hygiene products: how far have we come in 6000 years? Periodontol 2000. 1997;15:7-14.

39. Kang CS, Wang FW, Qu HB, Fan YS, Ma CC. A brief history of the development of oral care products. Oral Care Industry. 2018;28(01):6-7.

40. Goh EXJ, Lim LP. Fact or fiction? Powered Toothbrushing is more effective than manual Toothbrushing. Oral Health Prev Dent. 2017;15(1):23-32.

41. China industry information network. http://www.chyxx.com/industry/201 905/735793.html Accessed 15 Feb 2020.

42. Cheng L, Liu W, Zhang T, Xu T, Shu YX, Yuan B, Yang YM, Hu T. Evaluation of the effect of a toothpaste containing Pudilan extract on inhibiting plaques and reducing chronic gingivitis: a randomized, double-blinded, parallel controlled clinical trial. J Ethnopharmacol. 2019;240:7.

43. Huang XL, Liu MD, Li JY, Zhou XD, Cate JM. Chemical composition of Galla chinensis extract and the effect of its main component(s) on the prevention of enamel demineralization in vitro. Int J Oral Sci. 2012;4(3):146-51.

44. Zhang X, Wen D, Liang J, Lei J. How the public uses social media wechat to obtain health information in China: a survey study. BMC Med Inf Decis Making. 2017;17(S2):66.

45. Zhang D, Junsheng GU, Shao RS. A cluster analysis of college students' health information acquisition channels:active seeking and accidental exposure. Chin J J Commun. 2015:05:81-93.

\section{Publisher's Note}

Springer Nature remains neutral with regard to jurisdictional claims in published maps and institutional affiliations.

Ready to submit your research? Choose BMC and benefit from:

- fast, convenient online submission

- thorough peer review by experienced researchers in your field

- rapid publication on acceptance

- support for research data, including large and complex data types

- gold Open Access which fosters wider collaboration and increased citations

- maximum visibility for your research: over $100 \mathrm{M}$ website views per year

At $\mathrm{BMC}$, research is always in progress.

Learn more biomedcentral.com/submissions 